\title{
REFLECTION
}

\section{How Can Primary Care Cross the Quality Chasm?}

\author{
Leif I. Solberg, $M D^{1}$ \\ Kurtis S. Elward, MD, MPH \\ William R. Pbillips, MD, MPH \\ James M. Gill, MD, MPH \\ Grabam Swanson, MD, MSc ${ }^{5}$ \\ Deborab S. Main, $P b D^{6}$ \\ Barbara P. Yawn, MD, MSc ${ }^{7}$ \\ James W. Mold, MD, MPH ${ }^{8}$ \\ Robert L. Pbillips, Jr, MD, MSPH \\ for the NAPCRG Committee on \\ Advancing the Science of Family \\ Medicine
${ }^{1}$ HealthPartners, Minneapolis, Minnesota
${ }^{2}$ University of Virginia, Charlottesville, Virginia
${ }^{3}$ University of Washington, Seattle, Washington
${ }^{4}$ Delaware Valley Outcomes Research, Newark, New Jersey
${ }^{5}$ McMaster University, Hamilton, Ontario, Canada
${ }^{6}$ University of Colorado, Denver, Colorado
${ }^{7}$ Olmsted Medical Center, Rochester,
Minnesota
${ }^{8}$ University of Oklahoma, Oklahoma City, Oklahoma
${ }^{9}$ Graham Center, Washington, DC

Conflicts of interest: none reported.

\section{CORRESPONDING AUTHOR}

Leif I. Solberg, MD

HealthPartners Research Foundation

PO Box 1524, MS\#21111R

Minneapolis, MN 55440-1524

leif.i.solberg@healthpartners.com

\begin{abstract}
The chasm between knowledge and practice decried by the Institute of Medicine (IOM) is the result of other chasms that have not been addressed. They include the chasm between what we know and what we need to know to improve care; the chasm between those who provide primary care and those who do not fund, study, support, or publish practical primary care studies; and the chasm between research and quality improvement (QI). These chasms are a result of problematic concepts, attitudes, traditions, time frames, and financing approaches among the various participants. If we are to facilitate the production and use of the knowledge needed for primary care to cross IOM's chasm, major changes are needed. These changes include the following: (1) admission by all primary care professions that we have quality problems that require our unified attention and action; (2) conversion of the paradigm from "translate research into practice" to "optimizing health and health care through research and QI"; (3) development and facilitation of more partnerships among clinicians, researchers, and care delivery leaders for engaged scholarship in both research and QI; (4) modification of the agendas and methods of funders and researchers so they emphasize the problems of patients and patient care and support practical time frames and research designs; and (5) facilitation by funders and journals of the dissemination and implementation of lessons from $\mathrm{QI}$ and practical research.
\end{abstract}

Ann Fam Med 2009;7:164-169. DOI: 10.1370/afm.951

\section{INTRODUCTION}

T The decades-old concerns about the quality and costs of American health care were heightened by the 1999 and 2001 reports from the Institute of Medicine (IOM) ${ }^{1,2}$ The 2001 report created a dramatic image in its title, Crossing the Quality Chasm, and in its frequently quoted statement, "between the care we have and what we could have lies not just a gap but a chasm.". ${ }^{11}$ Responding to this and other pressures, the National Institutes of Health (NIH) launched a revolution in funding research through what is called the Roadmap and its Clinical and Translational Science Awards for academic health centers. ${ }^{3,4}$ Although this revolution is aimed at increasing translational research, most of the NIH emphasis appears to be on what is called T1 translation, converting what has been learned in basic science into clinical research. Without equal emphasis on T2 (creating patient-specific comparative effectiveness evaluations and guidelines) and T3 (learning how to implement T2 lessons), as well as making all 3 efforts bidirectional, the chasm will remain (see Dougherty and Conway for an excellent description of this concept). ${ }^{5,6}$

Unfortunately, most studies and commentaries indirectly blame physicians for the quality chasm because of their failure to translate researchbased evidence into practice. Although there is much need for primary care leaders and clinicians to improve delivery of medical care, we suggest 
that the deficiencies are shared by many, including those who think the problem is simply one of translation from science into practice. Blaming those who provide primary care misses all the other chasms that have contributed to the one highlighted by the IOM:

1. The chasm between what we know and what we need to know to improve care

2. The chasm between care delivery and those who do not fund, study, support, or publish practical studies that address the real problems of patients and care

3. The chasm between research and quality improvement

The management school professor Andrew Van de Ven appears to have come much closer to understanding these chasms. ${ }^{7-9} \mathrm{He}$ and his colleagues note that there are gaps between knowledge and practice in a wide variety of fields and industries; they conclude that these gaps are not caused by problems with knowledge translation or by any basic incompatibility between practice knowledge and research knowledge. Instead, they propose that the main deficiency is in the coproduction of relevant and applicable knowledge. Their solution is to encourage what they term engaged scholarship, where researchers work in partnership with practicing physicians and medical care leaders on problems identified in practice, using the methods of both practical research and quality improvement.

Tunis, Stryer, and Clancy have made a similar argument advocating more practical clinical trials, which they define as studies "for which the hypothesis and study design are developed specifically to answer the questions faced by decision makers" at all levels. ${ }^{10}$ Stange, Miller, and McWhinney note that "borrowed and adapted knowledge is insufficient" for generalist practice improvement; we need to be involved in creating our own knowledge. ${ }^{11}$ They advocate a multimethod, transdisciplinary, participatory approach to knowledge creation that, because of this involvement, will be more readily incorporated into practice.

If we are to bridge these chasms we need to reduce the many conceptual, attitudinal, and practical barriers that stand in the way, many of which were also recently identified by an IOM Forum on Advancing Quality Improvement Research. ${ }^{12}$ In this essay, we describe the barriers and recommend actions to reduce them.

\section{BARRIERS}

\section{Concepts and Attitudes}

Current concepts and attitudes about primary care practice, research, and quality improvement contribute to the chasms described earlier. The following are the most important.
Primary care leaders seem reluctant to fully admit that there is a serious quality problem. Not only is perfect care rare, but to attain it, the culture and approach of care delivery needs fundamental rethinking, not simply more funds and tools like the electronic medical record. Family medicine, internal medicine, and pediatrics organizations in the United States and Canada have all issued reports describing some of the changes that primary care physicians should make ${ }^{13-15}$ (American College of Physicians: http://www.acponline.org/; American Academy of Pediatrics Residency Review and Redesign in Pediatrics project [R3P]: http://www.innovationlabs.com/r3p_public). None of these reports, however, explicitly acknowledge a quality of care problem, and none call for improvement actions by primary care as a whole.

Clinicians perceive their responsibility to be limited to individual patients. As a result, clinicians tend to regard improvement of care for patient populations and cooperation with research as either unnecessary or someone else's job. For most, care improvement is limited to keeping up with advances in care and science, not system redesign or organizational change. Training and orientation have been focused on the care of individual patients, face-to-face and one at a time, so that is also how most tend to approach improvement.

Policy makers, funders, and researchers assume the main problem is lack of translation, not lack of knowledge. This assumption is a big barrier to improving care, because it suggests that clinicians should simply transfer what has been proved in randomized controlled trials into common practice. It regards such knowledge as valid, complete, applicable, and easily implemented, none of which is true for much of this evidence. In fact, relevant evidence is lacking for most of the decisions needed in patient care, and little more is known about how to make changes to improve care. Implementation (called T3 translation in the NIH paradigm) is still a fairly primitive science. ${ }^{16,17}$

Researchers perceive that their responsibility is limited to posing, answering, and publishing about questions of interest to them and funders. As a result, there is little concern about whether their work solves day-to-day problems for clinicians or patients. Their proposals and the results of their studies need only be acceptable to other academics or policy makers, and the only dissemination needed is through publication in academic journals; implementation is someone else's job.

The criteria and values used by the scientific review panels that make funding decisions are not aligned with the goal of care improvement. Even those researchers who are motivated to undertake studies useful to practice face this barrier to funding them. Designs other than randomized control trials that are more useful for practice and with greater potential for generalizability have trouble 
achieving a fundable score in the review process. Tunis and colleagues have described the need for funding bodies to find ways to support more pragmatic or practical clinical trials. ${ }^{10}$

Health care managers are not accustomed to relying on evidence for decision making. Most serious quality improvement depends on practice systems, and the necessary organizational changes require leadership and support from health care managers and decision makers. Walshe and Rundall point out that managers are even less comfortable with relying on evidence and measurement than are clinicians. ${ }^{18}$

Primary care is spectacularly disunited. Each primary care specialty seems to view the world through its own lens, even though they have more common interests than differences. Each cannot afford to address these gaps separately, particularly when they often work in the same organizations.

\section{Practical Barriers}

In addition to the conceptual and attitudinal barriers described above, there are also many practical barriers. Both researchers and clinicians face increasing pressures of time, money, and rising expectations. If clinicians are to spend part of their workday on quality improvement (QI) and research partnerships, and if researchers are to invest serious time in implementation, we must find ways to pay for that time.

Researchers are also pressured by deadlines and the constant need to search and compete for funding for their research time. Typically, research grant funds run out before publications are completed. They rarely cover the time required to help implement research lessons in practice. Only in unusual settings or programs such as the Veterans Administration QUERI (Quality Enhancement Research Initiative) program has implementation been both encouraged and supported financially. ${ }^{19,20}$ The QUERI mission is "to enhance the quality of VHA health care by implementing clinical research findings into routine care," so its projects typically involve collaborations between researchers and organizational leaders. ${ }^{21}$

Another practical problem is that researchers, clinicians, and care delivery leaders are not accustomed to working collaboratively across the research-practice boundary, and there are few opportunities to do so. Their cultures, language, time frames, and work settings are quite different, so they do not know how to talk or work together on a common project. Each group has had to learn how to behave collaboratively within its own domain, because collaboration is increasingly the only way to conduct research or care for patients. Collaborating across domains is another matter.

The difference in time frames raises another prob- lem. Care delivery is undergoing constant changes, many of which constitute natural experiments from which we could learn important lessons. These care changes, however, usually come up too quickly to allow the usual approach to development and funding of a research proposal that could evaluate their effects, and there are rarely research-practice connections that could coordinate the design and implementation of studies of these innovations.

QI has increasingly become a part of most large care delivery organizations, although it has still not penetrated into many small practices that provide most medical care. Even in organizations where QI is ongoing, good evaluation and publication of generalizable lessons are infrequent. This is partly due to a deficit in the knowledge and experience about how to evaluate and report QI efforts, but it is also seriously impeded by the requirements of institutional review boards (IRBs) and journal editors.

Although IRBs are charged with the protection of human subjects, most still hold that publishing or presenting findings from QI efforts turns them into research projects that require prospective review and approval. Ironically, that approach puts IRBs in the position of blocking dissemination of QI lessons that could improve patient care. Because IRBs usually refuse to review projects retroactively, all QI projects would have to undergo a research-type review on the front end, even though only a minority might produce publishable lessons. This problem is further complicated by journal editor requirements for IRB approval. A Hastings Center expert panel has proposed a special review mechanism for overlapping QI-research projects, but Grady's commentary on this report concluded that trying "to make a sharp conceptual distinction between QI and human subjects research is unlikely to succeed." 22,23

\section{RECOMMENDED SOLUTIONS}

There appear to be at least 5 closely related bridges for crossing the quality chasm.

1. Primary care professions must admit we have quality problems that require unified attention and action.

There is an understandable tendency for physicians to be defensive about the quality of their care, but practice changes will require clinicians and care delivery leaders to be actively involved in the development and testing of practice systems. Without acknowledging the quality problems, such active involvement is unlikely to happen, because system changes are much more effective in improving practice than exhortation, education, or individual clinicians trying harder. ${ }^{24-29}$ Ideally, the boards and professional associations of all 3 primary care specialties will take the lead, acting on 
behalf of primary care as a whole rather than their own piece of turf.

2. Convert the paradigm from "translate research into practice" to "optimize health and health care through research and QI."

This reformulation by Kottke et al of a misleading paradigm better identifies the real customers for research as patients and care. ${ }^{30}$ There is an urgent need to devote a much greater share of research to solving the applied problems of care delivery that frustrate leaders, clinicians, and patients. Improving care will require the support and involvement of the people and organizations that deliver care in identifying problems, creating knowledge, and applying it. The other problem with the translational research term is that it reflects the inappropriate view of a one-way movement that is better seen as a two-way street. ${ }^{6}$

3. Develop and facilitate more partnerships among clinicians, researchers, and care delivery leaders for engaged scholarship in both research and QI.

The starting point for stimulating such partnerships is for funding agencies to require most practice-oriented research proposals to involve partnerships from beginning to end. Most clinicians will be receptive to involving such partnerships if researchers address their problems in respectful ways. Both Robinson and Gould's survey of British general practitioners and the rapid growth of practice-based research networks in the United States demonstrate this. ${ }^{31,32}$

Such research and QI partnerships will need to include practice leaders. These are the individuals who will develop and implement the necessary changes in practice systems, so their involvement in identifying questions and conducting research and QI studies is critical. Lorenz et al conducted focus groups of clinicians and managers and concluded that neither group was comfortable with making use of primary literature, preferring instead to rely on trusted experts' opinions. ${ }^{33}$

If funding agencies changed their requests for proposals, methods, and priorities tomorrow, however, few researchers, care delivery leaders, or clinicians would be ready for it. Helping researchers make this transition may be challenging, but they are used to adapting to whatever is needed to obtain grant funding. Helping clinicians change may be a bigger challenge. It may require early intervention, changing physician training to prepare for assuming an active role in the production and implementation of new knowledge. It may also benefit from a decentralized infrastructure of technical assistance for both QI and research partnerships, something similar to the extension agent approach used so effectively in agriculture.

Certifying boards have already made the transition from testing the physician's acquisition of knowledge to measuring its application in care situations, so they could also require involvement in QI and research partnerships. Nascent steps in this direction have been taken by the boards of each US primary care specialty, as well as by the Canadian College of Family Physicians. These programs give physicians credit for measuring their care before and after implementing individual QI efforts. Even so, however, they are aimed at individual physicians rather than at the system changes needed at the whole-practice level, and they do not reward participation in research partnerships or implementation of research and QI lessons.

Training and incentives to form partnerships will not be enough unless funders also permit (or require) that some of the grant funds be used to pay for the time of these partners, for clinicians to support research as well as for researchers to support implementation and spread efforts. The VA's QUERI has shown that this can be done, and that it can lead to large improvements in the quality of care delivered. A systematic review by Innvaer et al suggested that simply increasing personal contacts and relationships between researchers and care leaders is an important facilitator of using evidence in making policy decision. ${ }^{34}$ To do so will require funding.

4. Funders and researchers should modify their agendas and methods so that they emphasize the problems of patients and patient care and support practical time frames and research designs.

What if funders convened meetings of clinicians and operational leaders, as well as researchers, to identify their research agendas? Those delivering care know some of what they need to know, while the researchers can identify methodological issues and can formulate the questions in answerable terms. One early example of clinicians generating researchable questions comes from FPIN (Family Physicians Inquiries Network at http://www.fpin.org). FPIN has developed a mechanism to identify questions that arise in practice, prioritize them through a voting process, and then answer them through systematic literature reviews. FPIN has found that about $80 \%$ of questions identified as important by network members cannot be answered from existing evidence and represent potential research topics.

It is equally important that the reviewers of these practice-generated proposals be willing to consider case studies, observational and quasi-experimental designs, qualitative and mixed methods, practical clinical trials, and carefully evaluated quality improvement projects. Tunis et al described practical clinical trials, and Glasgow et al have provided recommendations to increase their relevance to clinicians and policy makers. ${ }^{10,35}$ We must also develop ways to study 
and learn from the natural innovations now prevalent in care delivery.

5. Funders and journals should facilitate the dissemination and implementation of lessons from QI and practical research.

It will also be necessary to require that proposals include and budget for dissemination of lessons and spread of implementation, both locally and generally. In a study by Bodenheimer et al of the practice-based research network grantees from the Robert Wood Johnson Foundation's effort to transform primary care practice, he found that "approaching practices with a time-limited project mentality can interfere with a process of permanent practice change." ${ }^{\prime \prime 6}$

When QI projects and natural experiments in care delivery produce potentially generalizable lessons, we also need ways to publish these findings. A modified, sometimes retrospective, IRB-like review process must be available to assure that reasonable human subject protections were used while avoiding current barriers to dissemination. The AAFP, NAPCRG, or a consortium of primary care organizations could sponsor a national IRB that was skilled in the issues of this type of work. Funding and technical support are needed for such a vehicle as a way to bridge the gap between lessons, their generalized awareness, and their use.

In conclusion, to create the new knowledge that will lead to improvements in the health of patients and communities, we must develop a new approach to primary care research and quality improvement. It will require changes in concepts, attitudes, expectations, and methods for funders, researchers, practice leaders, clinicians, and systems of care. It will also require an increase in funding for this type of research by the federal government, but whether that comes from modifications in NIH, expansion of AHRQ and other smaller agencies, or the creation of a new agency is beyond the scope of this article.

These recommendations require serious discussion and action. The health care policy makers, research funders, payers, and journal editors who demand that clinicians improve their practices must also support innovations in the approach to research and quality improvement in primary care. The chasm between knowledge and care is wide and deep. Building bridges across it will require imagination, innovation, and partnerships.

To read or post commentaries in response to this article, see it online at http://www.annfammed.org/cgi/content/full/7/2/164.

Submitted February 18, 2000; submitted, revised, July 3, 2008; accepted July 13, 2008.

Key words: Diffusion of innovation; evidence-based medicine; primary health care; research support; total quality management
Disclaimer: This article represents the opinions of the authors, all of whom are members of the Committee to Advance the Science of Family Medicine of NAPCRG (North American Primary Care Research Group). It does not, however, represent official policy of that group, but was created to stimulate discussion and changes that will, in the opinion of the authors, facilitate the broader and more useful involvement of primary care clinicians and organizations in research and quality improvement.

\section{References}

1. Institute of Medicine. Crossing the Quality Chasm: A New Health System for the 21st Century. Washington DC: National Academy Press; 2001.

2. Institute of Medicine. To Err Is Human. Washington, DC: National Academy Press; 1999.

3. Zerhouni EA. Translational and clinical science-time for a new vision. N Engl J Med. 2005;353(15):1621-1623.

4. Zerhouni EA. US biomedical research: basic, translational, and clinical sciences. JAMA. 2005;294(11):1352-1358.

5. Westfall JM, Mold J, Fagnan L. Practice-based research-"Blue Highways" on the NIH roadmap. JAMA. 2007;297(4):403-406.

6. Dougherty D, Conway PH. The "3T's" road map to transform US health care: the "how" of high-quality care. JAMA. 2008;299(19):2319-2321.

7. Van de Ven A, Johnson PE. Knowledge for theory and practice. Acad Manage Rev. 2006;31(4).

8. Van de Ven A, Zlotkowski E. Toward a scholarship of engagement: a dialogue beween Andy Van de Ven and Edward Zlotkowski. Acad Mgmt Learning Education. 2005;4(3):355-362.

9. Van de Ven AH. Engaged Scholarship: A Guide for Organizational and Social Research. New York, NY: Oxford University Press; 2007.

10. Tunis SR, Stryer DB, Clancy CM. Practical clinical trials: increasing the value of clinical research for decision making in clinical and health policy. JAMA. 2003;290(12):1624-1632.

11. Stange KC, Miller WL, MCWhinney I. Developing the knowledge base of family practice. Fam Med. 2001;33(4):286-297.

12. Institute of Medicine. Advancing Quality Improvement Research: Challenges and Opportunities, Workshop Summary. Washington, DC: National Academies Press; 2007.

13. Martin JC, Avant RF, Bowman MA, et al. The future of family medicine: a collaborative project of the family medicine community. Ann Fam Med. 2004;2(Suppl 1):S3-S32.

14. Family Medicine in Canada-Vision for the Future. Mississauga, Ontario: College of Family Physicians of Canada; 2004.

15. Meyers FJ, Weinberger SE, Fitzgibbons JP, Glassroth J, Duffy FD, Clayton CP. Redesigning residency training in internal medicine: the consensus report of the Alliance for Academic Internal Medicine Education Redesign Task Force. Acad Med. 2007;82(12):1211-1219.

16. Fixsen DL, Naoom SF, Blase KA, Friedman RM, Wallace F. Implementation Research: A Synthesis of the Literature. Tampa, FL: University of South Florida; 2005.

17. Rubenstein LV, Pugh J. Strategies for promoting organizational and practice change by advancing implementation research. J Gen Intern Med. 2006;21(Suppl 2):S58-S64.

18. Walshe K, Rundall TG. Evidence-based management: from theory to practice in health care. [IV-V.]. Milbank Q. 2001;79(3):429-457.

19. Smith JL, Williams JW, Owen RR, Rubenstein LV, Chaney E. Building QUERI research-clinical partnerships to disseminate collaborative care for depression. US Department of Veterans' Affairs. Health Services Research \& Development Service. 2007 National Meeting.

20. Smith MW, Barnett PG. QUERI and the economics of implementation studies. Implement Sci. 2007;3(1)20. 
21. Hagedorn H, Hogan M, Smith JL, et al. Lessons learned about implementing research evidence into clinical practice. Experiences from VA QUERI. J Gen Intern Med. 2006;21(Suppl 2):S21-S24.

22. Grady C. Quality improvement and ethical oversight. Ann Intern Med. 2007;(Apr):16.

23. Lynn J, Baily MA, Bottrell M, et al. The ethics of using quality improvement methods in health care. Ann Intern Med. 2007;146(9):666-673.

24. Bodenheimer T. Interventions to improve chronic illness care: evaluating their effectiveness. Dis Manage. 2003;6(2):63-71.

25. Fleming B, Silver A, Ocepek-Welikson K, Keller D. The relationship between organizational systems and clinical quality in diabetes care. Am J Manag Care. 2004;10(12):934-944.

26. Solberg LI, Trangle MA, Wineman AP. Follow-up and follow-through of depressed patients in primary care: the critical missing components of quality care. J Am Board Fam Pract. 2005;18(6):520-527.

27. Shojania KG, Ranji SR, McDonald KM, et al. Effects of quality improvement strategies for type 2 diabetes on glycemic control: a meta-regression analysis. JAMA. 2006;296(4):427-440.

28. Bergeson SC, Dean JD. A systems approach to patient-centered care. JAMA. 2006;296(23):2848-2851.

29. Solberg LI, Klevan DH, Asche SE. Crossing the quality chasm for diabetes care: the power of one physician, his team, and systems thinking. J Am Board Fam Med. 2007;20(3):299-306.
30. Kottke TE, Solberg LI, Nelson AF, et al. Optimizing practice through research: a new perspective on an old problem. Ann Fam Med. 2008; 6(5):459-462.

31. Green LA, Hickner J. A short history of primary care practice-based research networks: from concept to essential research laboratories. J Am Board Fam Med. 2006;19(1):1-10.

32. Robinson G, Gould M. What are the attitudes of general practitioners towards research? Br J Gen Pract. 2000;50(454):390-392.

33. Lorenz KA, Ryan GW, Morton SC, Chan KS, Wang S, Shekelle PG. A qualitative examination of primary care providers' and physician managers' uses and views of research evidence. Int J Qual Health Care. 2005;17(5):409-414.

34. Innvaer S, Vist G, Trommald M, Oxman A. Health policy-makers' perceptions of their use of evidence: a systematic review. J Health Serv Res Policy. 2002;7(4):239-244.

35. Glasgow RE, Magid DJ, Beck A, Ritzwoller D, Estabrooks PA. Practical clinical trials for translating research to practice: design and measurement recommendations. Med Care. 2005;43(6):551-557.

36. Bodenheimer T, Young DM, MacGregor K, Holtrop JS. Practicebased research in primary care: facilitator of, or barrier to, practice improvement? Ann Fam Med. 2005;3(Suppl 2):S28-S32. 